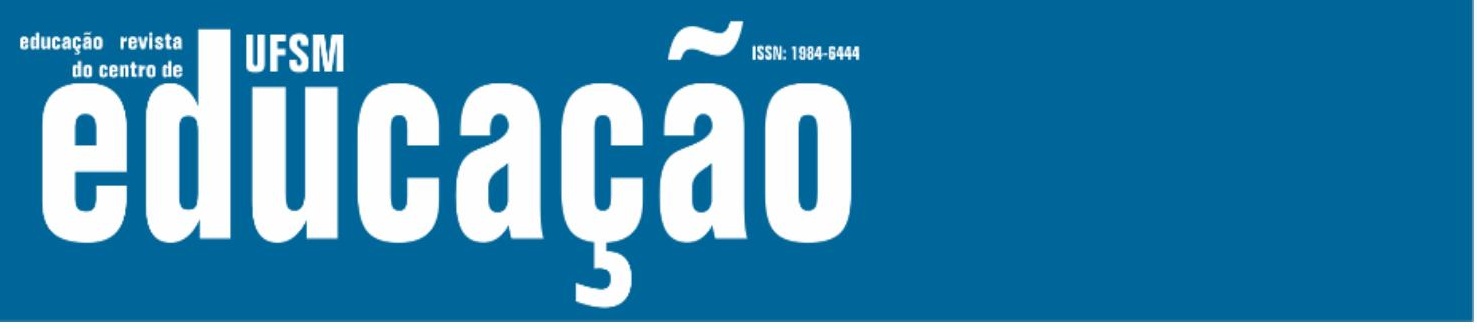

ISSN: 1984-6444 | http://dx.doi.org/10.5902/1984644440558

\title{
Regulação por resultados: leitura de pressupostos teóricos educacionais aliada a um documento do Banco Mundial
}

\author{
Results-based regulation: theoretical and educational assumptions \\ reading coupled with a World Bank's document
}

\author{
Roque Strieder \\ Professor doutor na Universidade do Oeste da Santa Catarina, Joaçaba, Santa Catarina, Brasil. \\ striederroque@gmail.com - https://orcid.org/0000-0002-0007-7628 \\ Aline Bettiolo dos Santos \\ Doutoranda na Universidade do Oeste da Santa Catarina, Joaçaba, Santa Catarina, Brasil. \\ a.bettiolo.santos@unoesc.edu.br - https://orcid.org/0000-0001-8933-3845
}

Recebido em 07 de janeiro de 2019

Aprovado em 09 de janeiro de 2019

Publicado em 05 de maio de 2021

\section{RESUMO}

O trabalho tem por objetivo refletir sobre pressupostos teóricos educacionais considerados fundamentais para a regulação por resultados. São focalizados pressupostos modernos e contemporâneos, bem como é abordado um documento do Banco Mundial, com objetivo de perceber o tom dos pressupostos assumidos por essa organização que exerce interferência na formação humana. Quanto aos procedimentos metodológicos, a seleção do documento também está vinculada uma pesquisa maior em processo, na qual se problematiza a regulação por resultados. Considera-se que os pressupostos da modernidade mascaram a fragmentação de saberes sob ênfase de especialidade. Já os contemporâneos convidam a outros pensares, como oportunidade de fazer frente e resistir às lógicas de servidão e de (de)formação humana, além de enriquecer as vivências investigativas com outras reflexões. Quanto ao documento, percebe-se o predomínio da linguagem da empresa, cujo tom sinaliza aportes teóricos modernos. Assim, traduzir o conhecimento em resultados quantificáveis é uma preocupação central da agência, de modo a conservar as relações capitalistas de produção.

Palavras-chave: Formação humana; Pressupostos educacionais; Regulação por resultados. 


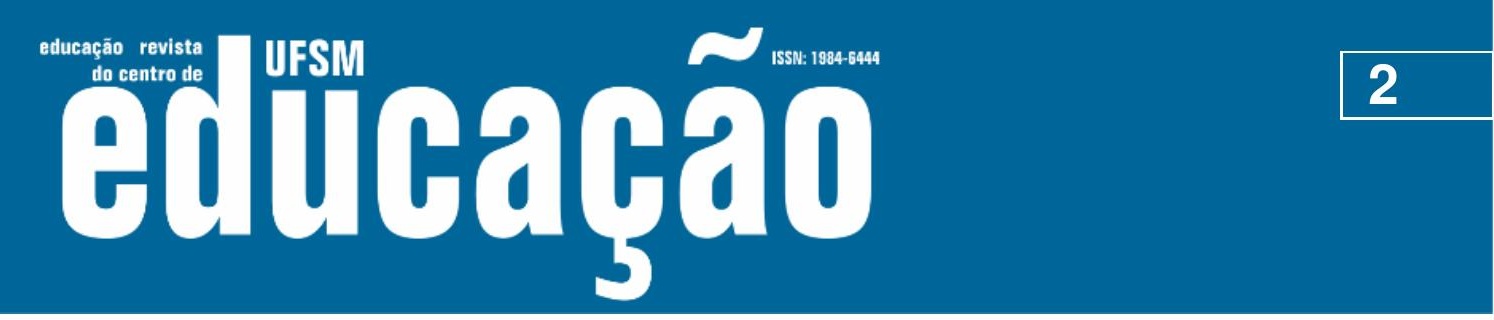

ISSN: 1984-6444 | http://dx.doi.org/10.5902/1984644440558

\section{ABSTRACT}

The study aims to think over theoretical and educational assumptions in parallel to results-based regulation. Modern and contemporary assumptions are highlighted, besides addressing a World Bank's document in order to perceive the tone of assumptions made by that organization which interferes in human development. About the methodological procedures, choice of document is also linked to a bigger research in process, in which results-based regulation is discussed. We consider assumptions of modernity obscure fragmentation of knowledge under specialization. On the other hand assumptions of contemporaneity invite us to have other thoughts and it is an opportunity of resisting to the servitude and human deformation logic and additionally, that prospect is able to improve investigative experiences with other thoughts. About the document, business speech is predominant whose tone indicates modern assumptions. Thus, translating knowledge in measurable results is a key concern of the agency and it preserves the capitalist relations of production.

Keywords: Human formation; Educational assumptions; Results-based regulation.

\section{Introdução}

Refletir sobre políticas de regulação leva-nos a problematizar a configuração do Estado no cenário contemporâneo, mas também os pressupostos teóricos educacionais envolvidos nos processos formativos ao longo da história. A respeito do Estado, destacamos que, o Brasil, a partir da década de 1990, tem seu perfil de Estado alterado em decorrência das dinâmicas econômicas e políticas que já se desenvolviam em âmbito mundial, nutridas pela força do fenômeno do neoliberalismo.

À luz desse fenômeno, que foi discutido por Dardot e Laval (2016) como a nova razão do mundo, tivemos a expansão da esfera privada, por meio das privatizações de empresas públicas, bem como o chamado enxugamento do Estado, de modo a corroborar o princípio de menor interferência no mercado. Tais reconfigurações foram justificadas pela necessidade de adequação às demandas neoliberais, cujas ideias força são resultado, eficácia e eficiência, ou seja, um linguajar empresarial com perspectivas neoliberais.

Nessa perspectiva, reconfigurar o papel do Estado também teve como base argumentos referentes à burocratização e à ineficiência o que trazia prejuízos a sua 


\section{Autตaดูão}

ISSN: 1984-6444 | http://dx.doi.org/10.5902/1984644440558

performance - desempenho - frente aos contextos econômicos e políticos da época. Para responder às demandas emergentes, suas responsabilidades com setores sociais foram minimizadas e essas, transferidas para a sociedade e para o mercado, o que é possível entendermos como descentralização. Entretanto, Estado enxuto não significa completamente mínimo, pois, ao passo que houve transferência de responsabilidades, o mercado recebeu mais oportunidade de oferecer serviços como o setor público. Portanto, ampliou sua extensão e, por conseguinte, seus lucros. No que se refere ao Estado, o mínimo não significa ser fraco, com perda de poder decisório, porque o mínimo é para setores sociais, nos quais, incluímos educação e saúde, mas é ainda máximo para o econômico, isto é, para o mercado.

As ideias de Harvey (2011) nos ajudam a argumentar sobre o perfil mínimo e máximo do Estado, pois o autor discute a história e as implicações do neoliberalismo sem perder de vista a valorização da iniciativa privada, desregulação de setores antes conduzidos pelo Estado e que passam a ser libertos de sua interferência, aspectos que estão ligados a um perfil mínimo. Na direção do perfil máximo, o autor entende que "[o Estado] cria condições favoráveis à acumulação lucrativa de capital pelos capitalistas domésticos e estrangeiros" (HARVEY, 2011, p. 17), o que sinaliza, para nós, um Estado regulador que não é neutro, nem alheio aos interesses burgueses de manutenção da sociedade capitalista.

$\mathrm{Na}$ lógica de manter os imperativos do capital, consideramos que os interesses das pessoas que integram o Estado estão sintonizados a um grupo social específico em detrimento dos demais. Se ao grupo burguês a prioridade é o lucro, as repercussões das reformas nos setores sociais são camufladas, isto é, propagandeadas com um linguajar que pretende convencer as pessoas de que são ações necessárias e inadiáveis, cujas consequências são benéficas a toda população. Já na década de 1990, um dos argumentos favoráveis aos ajustes era o de modernizar Estado, economia e sociedade. Todavia, de outra perspectiva que não é a empresarial, a reforma consistiu de uma estratégia para conservar a relação de exploração entre capital e trabalho. Nos termos de Behring (2003), o tom da referida década caracteriza-se por uma contrarreforma, o que a autora define como 


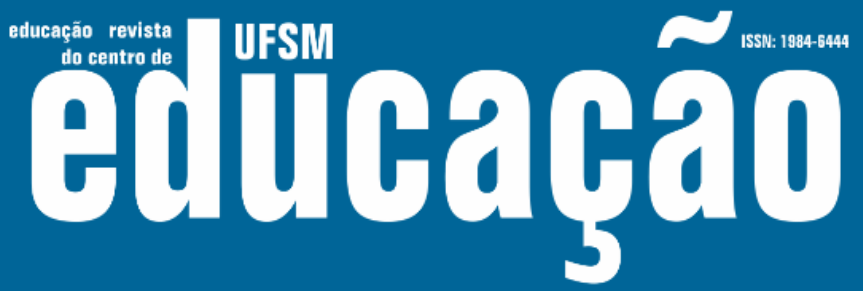

ISSN: 1984-6444 | http://dx.doi.org/10.5902/1984644440558

pressupostos teóricos capazes de fazer frente à razão neoliberal que ganha força com o avanço do capitalismo e com princípios neoconservadores que marcam os contextos históricos recentes.

A abordagem deste estudo é qualitativa, por valorizarmos o processo de reflexão sobre pressupostos teóricos educacionais e sobre o tema da regulação em paralelo aos resultados oriundos de uma fonte empírica. Por situarmos o trabalho na perspectiva qualitativa, significa que nosso entendimento de ciência não se limita à ordem dos números, do rigor matemático e das descrições dissociadas da dinâmica histórica, mas, ao contrário, que a busca para estabelecer relações do objeto de estudo com variados aspectos do sistema social, a compreensão de sua estrutura mais íntima, o pesquisador e sua capacidade de interpretar, analisar, e refletir constituem aspectos dessa abordagem, a qual não se resume à escolha de uma técnica de pesquisa.

Consoante a Gamboa (2003), é um equívoco abordar a pesquisa qualitativa como técnica de tratamento de dados, pois, entre a escolha de abordagem quantitativa e qualitativa estão implícitas opções teóricas, epistemológicas e filosóficas. Para o autor, "na maioria das situações se desconhecem as referências históricas dessas abordagens e se ignoram seus pressupostos filosóficos. Daí porque essas abordagens científicas sejam tratadas apenas como técnicas de pesquisa" (GAMBOA, 2003, p. 395). Em vista disso, para além do dualismo entre pesquisa quantitativa e qualitativa, o que está em cena não é a utilização de técnicas de coleta e tratamento de dados e informações, mas, sim, diversas concepções de ciência e de epistemologia.

Ao que se refere à construção do texto, a problematização introdutória é seguida de duas seções e de uma subseção. Na primeira delas, construímos alguns apontamentos sobre pressupostos teóricos educacionais da modernidade e, em seguida, sobre pressupostos contemporâneos. Na subseção, abordamos um documento do Banco Mundial para perceber o tom dos pressupostos assumidos por essa organização que influencia no direcionamento da formação humana. 


\section{Aillbapẫ \\ 3}

ISSN: 1984-6444 | http://dx.doi.org/10.5902/1984644440558

\section{Pressupostos teóricos educacionais da modernidade: alguns apontamentos}

Por que pensar sobre regulação por resultados? Por que pensar em pressupostos teóricos educacionais criados na modernidade? Em princípio, situamos o tema da regulação como uma problemática relacionada ao papel do Estado na sociedade, que, por sua vez, não está isento da influência de organizações internacionais no delineamento das políticas educacionais, o que repercute nos processos educativos. Com isso, queremos dizer que as políticas, bem como os processos estão constituídos por pressupostos teóricos. Assim, refletir sobre os pressupostos trata-se de um exercício para também pensar na formação humana.

Em segundo lugar, embora a ênfase nos resultados esteja ligada aos aspectos neoliberais que implicam ser a lógica da empresa levada para o Estado e setores públicos, como a escola, com intensidades ampliadas ao longo do tempo. Essa ideia firma-se pelas incessantes contrarreformas, embora a raiz dessa ênfase não esteja na década de 1990, quando o neoliberalismo avançou no país. O conhecimento centrado na matematização remete a séculos anteriores, quando a ciência assumiu tamanha importância na sociedade, a ponto de apenas o saber quantificável tornar-se válido. Nesse sentido, a religião perdeu força para a razão e o conhecimento científico passou a ser um novo tipo de deus.

A partir das ideias de Prigogine e Stengers (1997), temos um panorama do projeto da ciência moderna, que tem, entre seus aspectos, a perspectiva de um mundo perfeito, equivalente a também chamada ordem natural. Em linhas gerais, a perfeição é atingida quando os fenômenos são completamente explicados, desencantados, tendo em vista a característica de previsibilidade, na qual a matemática dita leis. No século XVIII, a Inglaterra comemorou as descobertas de Newton, segundo os autores, considerando-o novo Moisés, a quem as tábuas da lei foram reveladas, por desvendar a linguagem que a natureza fala e à qual ela obedece. Assim, além de herói nacional, Newton tornou-se o símbolo da revolução científica europeia. 


\section{Autตaดูão}

ISSN: 1984-6444 | http://dx.doi.org/10.5902/1984644440558

O processo de desencantamento, do qual o triunfo newtoniano é resultante, envolve etapas, cujo ponto de partida consiste em isolar um fato central dentre um conjunto de fenômenos, e deste tudo será possível deduzir. A nosso ver, o isolamento de um objeto de estudo na concepção de Newton, a qual ilustra a perspectiva teórico-metodológica positivista, é descolado de um contexto histórico e a ênfase está no objeto pelo objeto, sem ser necessário estabelecer relações com outros campos de conhecimento. Nessa direção, a ciência domina a natureza com a lógica da universalidade, com o poder explicativo de um sistema de leis que indicam regularidade, equilíbrio e preveem o comportamento do fenômeno. Assim, sob o viés do positivismo há uma única verdade e ela é absoluta, isto é, o que é verdadeiro é o conhecimento científico traduzido pelo número.

No processo de desencantamento pela via da matematização do saber, também está inserida a relação sujeito-objeto e, aqui, entendemos sujeito enquanto protagonista nessa relação, como agente construtor de conhecimento. Porém, em uma leitura moderna e, sobretudo, positivista, o pesquisador está em segundo plano em relação ao objeto, em uma condição de receber a mensagem do objeto mas, não de interpretá-la ou de problematizá-la. Schaff (1995), ao discutir a tríade do processo cognitivo envolvendo sujeito, objeto e conhecimento, indica que no seu primeiro modelo, referindo-se à concepção positivista, o objeto atua sobre a percepção do sujeito, que é passivo, contemplativo e receptivo. O conhecimento, nessa relação, é reflexo, o objeto é central e o sujeito, como sublinhamos, distancia-se de uma característica atuante. Nas palavras do autor, "o produto deste processo - o conhecimento - é o reflexo, a cópia do objeto, reflexo cuja gênese está em relação com a ação mecânica do objeto sobre o sujeito. É por isso que qualificamos este modelo de mecanicista" (SCHAFF, 1995, p. 73).

Consideramos de igual modo que o segundo modelo sugerido por Schaff (1995) está articulado à noção de desencantamento de Prigogine e Stengers (1997) e aos pressupostos emblemáticos da modernidade. Diferente do modelo anterior, a predominância na relação sujeito-objeto está no sujeito, que assume o papel de criador da realidade. Isso corrobora a ideia de ser humano enquanto senhor do mundo, surgida com o avanço da ciência e inaugurada com a revolução científica no 


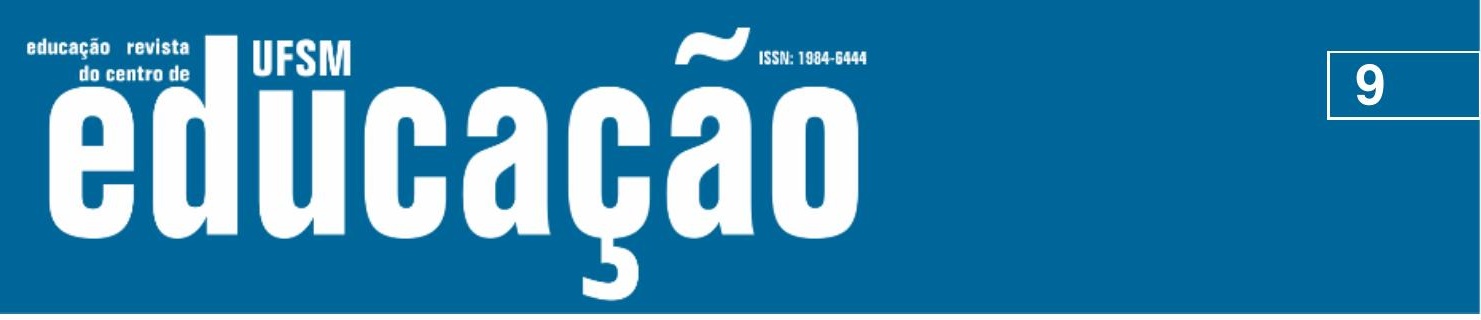

ISSN: 1984-6444 | http://dx.doi.org/10.5902/1984644440558

documento do Banco Mundial para perceber o tom dos pressupostos assumidos por essa organização, pois pressupostos teóricos e documentos internacionais oferecem direcionamento à formação humana. Diferente de circunscrever as questões do objeto pelo objeto, compreendemos que questionar os pressupostos é um exercício complexo e desafiador ao mesmo tempo, justamente porque os da modernidade estão firmados há alguns séculos. Assim, sua solidez, tende a ser reforçada, por tratar-se de pressupostos impregnados nas diversas dimensões da sociedade.

$\mathrm{Na}$ acepção de exercitar perguntas, a importância e o desafio de refletir sobre pressupostos teóricos também são registrados por Boaventura de Souza Santos (2008), o qual ressalta pluralidade de caminhos para conhecer os fenômenos, desde a perspectiva clássica, moderna, até perspectivas que questionam os pressupostos clássicos. A partir do autor, destacamos que essa pluralidade abrange a crise do paradigma dominante, com vistas ao paradigma emergente, cujos aspectos estão mais ligados à posição pós-moderna, que faz frente à abordagem da modernidade. A crise paradigmática sinaliza um período de transição em que se faz necessário voltar às coisas simples, à capacidade de formular perguntas simples. Os pressupostos clássicos ainda integram nossos viveres, mas isso não significa que outras questões não possam ser pensadas, aliás, a sociedade está em constante transformação e ignorar que ela e a história são dinâmicas é limitar nossa leitura de mundo e nossos viveres a condições de determinismo.

A educação também se insere na realidade em mudança e, assim, diferentes posicionamentos alcançam maior ou menor espaço no contexto da formação humana. A dimensão econômica segue repercutindo nos assuntos educacionais, de modo a exigir da escola uma formação que varia conforme estágio em que o capitalismo encontra-se. De acordo com Libâneo (2005, p. 16), "pensar e atuar no campo da educação, enquanto atividade social prática de humanização das pessoas, implica responsabilidade social e ética de dizer não apenas o porquê fazer, mas o quê e como fazer". Um dos problemas que se apresenta é quem se julga apto a decidir o que as escolas precisam fazer, no sentido de delinear políticas para a área e prescrever uma espécie de receituário de como atuar na prática das salas de aula. 


\section{Tisn Eutloab̧a}

ISSN: 1984-6444 | http://dx.doi.org/10.5902/1984644440558

Esses delineamentos, frequentemente, não partem das necessidades do cotidiano escolar, dos professores e dos alunos em si, tampouco parecem prestar atenção às diferenças existentes em termos econômicos, históricos e culturais entre as regiões. Logo, por que organizações internacionais e empresas estão muito interessadas na educação? Por que conseguem legitimar princípios nas escolas? Como podemos fazer frente e resistir à lógica empresarial que invade as políticas educacionais assim como as instituições escolares? Que formação humana é possível diante do predomínio da lógica de mercado?

Ainda que princípios empresariais - eficiência, eficácia e resultados - tenham despontado a partir da reestruturação produtiva do sistema capitalista com o consequente avanço neoliberal nas diversas regiões do planeta, defendemos que se situam no conjunto de pressupostos da modernidade. Segundo discorre Libâneo (2005), a ideia de formação geral para todos como condição de emancipação e de esclarecimento é ilustrativa de teorias modernas de educação, assim como as seguintes características: ênfase na racionalidade, progresso da ciência, cultura universal objetiva, educação como transmissão, separação entre razão e sujeito e paradigma da consciência, que privilegia a ação do sujeito sobre o objeto.

A nosso ver, os princípios empresariais constituem significativos limites ao que se refere a uma formação humana mais voltada aos viveres do próprio indivíduo e menos para o mercado. Na esteira de fragilidades formativas, agregamos pressupostos teóricos da modernidade, pois a partir dos aspectos focalizados nesta seção, percebemos que não há espaço para pensar fragmentação dos saberes e quanto a si mesmo, no sentido de levantar questões ligadas ao sentimento, imaginação, ou ainda à subjetividade, nesse caso, o que temos é a preponderância da razão matemática.

\section{$\mathrm{Na}$ contramão da abordagem clássica: anotações sobre pressupostos contemporâneos}

De um caminho diverso ao da abordagem clássica, os pressupostos contemporâneos são um convite para pensar o tema de estudo - regulação por 


\section{Autตaดูão}

ISSN: 1984-6444 | http://dx.doi.org/10.5902/1984644440558

resultados -, bem como a educação escolar de maneira mais ampla, sob um viés que valoriza as subjetividades, a virada da linguagem e a conseguinte mudança de agires. Assim, focalizamos os aspectos da autopoiese nesta seção, sustentando nossas anotações nos escritos de Humberto Maturana e Francisco Varela (1995; 1997).

Quando discorremos sobre regulação por resultados considerando a influência de uma Agenda Globalmente Estruturada para a Educação (AGEE), estamos mais propensos a discutir questões no âmbito da totalidade, objetividade, porque as agendas são estabelecidas pela economia política global, sem que problemas localmente percebidos sejam prioridades para organizações internacionais. O Banco Mundial evidencia na maioria de seus estudos a recorrência de os achados resultarem em fórmulas matemáticas e índices, o que reforça uma leitura moderna de que conhecer é quantificar, simplificando a complexidade da educação, da formação humana. Ainda sobre a Agenda, conforme anota Dale (2004, p. 455),

A AGEE introduz novas concepções sobre a natureza das forças globais e sobre como é que elas operam, e atribui estas transformações à mudança da natureza das forças supranacionais, não estando os valores culturais universais e os guiões imunes às forças da globalização, económica, política e cultural.

A partir desses apontamentos, inferimos que os pressupostos subjacentes á estrutura da Agenda e aos documentos produzidos por uma organização como o Banco Mundial sejam os da modernidade, já que está em jogo a definição de ideias para delinear políticas educacionais, cujo foco pode ser a formação de professores, alunos e, ainda, os respectivos currículos. Por outro lado, para além da noção de que somos apenas moldados e influenciados pelo meio, isto é, por políticas externas às fronteiras do país, é importante não perder de vista que também temos potencial para construir o meio. Nesse sentido, nosso destaque é para a ideia de acoplamento estrutural, em que interações com 0 ambiente possibilitam ir além das representações de uma realidade exterior, favorecendo a própria auto-organização, articulada à determinação estrutural do ser. Essa ideia situa-se na perspectiva da autopoiese, a respeito da qual Maturana e Varela $(1997$, p. 15) concebem que, 


\section{Althaห̧ão}

ISSN: 1984-6444 | http://dx.doi.org/10.5902/1984644440558

incompletos, absolutos, capazes de "melhorar a vida" empreendendo a nós mesmos, sendo mais competitivos, mais produtivos. Dessa forma, na eminência do neoliberalismo, a ideia de interdependência e de profanação parecem ser diminuídas. Em seus lugares, acreditamos que a autonomia ganha força, entretanto, uma autonomia associada a um egoísmo extremo e à lógica da indiferença.

Ainda com o objetivo de refletir sobre pressupostos teóricos educacionais em paralelo à regulação por resultados, na seção seguinte, realizamos uma sucinta abordagem de um documento do Banco Mundial, concentrando-nos na sua problematização introdutória, para perceber o tom dos pressupostos assumidos por essa organização, embora a dimensão de seus estudos não seja aqui esgotada. Assim, estamos inferindo que a linguagem pode sinalizar um pensamento reducionista, mas, talvez, também possa oferecer-nos traços de um pensamento sintonizado com a complexidade, mostrando que tal abordagem, em consonância com as observações de Morin (1998), não é um manual, mas uma motivação para pensar e seguir pensando.

\section{Entre pluralidades de pressupostos, que tom é assumido pelo documento?}

Apesar das forças diretivas do capital atuarem a fim de garantir a organização da economia global e sua manutenção, em conformidade com a premissa de uma AGEE, o Banco Mundial tenta relativizar o peso de suas recomendações no Relatório... (1999, p. 4)3 , ao destacar que possui a missão de "ajudar países a combater a pobreza e com profissionalismo alcançar resultados duradouros". Além disso, anota que "assiste clientes para identificar e implementar seus próximos passos estratégicos a fim de proporcionar a todos o acesso a uma educação de qualidade" (1999, p. 4). Nesse sentido, o trabalho da agência, segundo as anotações no texto publicado, envolve ouvir de perto seus clientes, trazer a eles o conhecimento global do Banco para sustentar as questões particulares de cada um, mostrar como a ajuda da instituição teve maior impacto e, assim, ao combinar as aspirações dos clientes com o próprio conhecimento da instituição em diversas áreas, são esperadas ações mais prováveis de contribuir para melhores resultados educacionais e redução da pobreza. 


\section{Tisn Ẽtlagha}

ISSN: 1984-6444 | http://dx.doi.org/10.5902/1984644440558

No entanto, o argumento de ouvir as questões dos clientes e a posteriori oferecer uma ajuda baseada em evidências, o que diz respeito aos estudos desenvolvidos pelo Banco em escala global, privilegiando aqueles com maior impacto, sinaliza alguma contradição quando as recomendações assumem o tom de dever - dever de os países ajudados (clientes) obterem melhores resultados educacionais e também o dever de reduzirem a pobreza. De acordo com o Relatório... (1999, p. 5, grifo no original), "ambos o Banco e o cliente devem aderir às operações e trabalhar juntos". Outras passagens do texto seguem ilustrando o tom de obrigação a cumprir: "qualidade de ensino e de aprendizagem deve ser questão proeminente", "deve haver, em políticas e ações - uma implacável concentração sobre aprendizagem" (1999, p. 5).

Refletir sobre pressupostos educacionais não se restringe a discutir a Agenda Global Estruturada para a Educação (AGEE) mas, ressaltar o envolvimento do Banco Mundial e sua preponderância na relação entre quem ajuda e quem recebe ajuda, visando minimizar a ideia de realizar um trabalho em conjunto com os chamados clientes. A nosso ver, trata-se da construção de um tipo de consenso acerca do que é estabelecido como prioridade dentro da dinâmica global e de um monitoramento de resultados em conjunto, cujo foco tende a ser questões voltadas à totalidade ao invés de relatividade, que enfatizam, portanto, a universalidade de processos educativos e eliminam as singularidades. Essa abordagem com tom universal diverge da abordagem característica de pressupostos contemporâneos, como o pensamento complexo, em que singularidades e complicações fazem parte de algumas das ideias-chave dessa perspectiva teórica. Para Morin (2005, p. 179),

O problema da complicação surgiu a partir do momento em que percebemos que os fenômenos biológicos e sociais apresentavam um número incalculável de interações, de inter-retroações, uma fabulosa mistura que não poderia ser calculada nem pelo mais potente dos computadores.

A partir do documento do Banco Mundial (1999), nossa leitura é que esse tom de pensar a educação enquanto um processo complexo não pode ser identificado no texto. Em contrapartida, a educação é considerada "a chave mais importante para o desenvolvimento e para o alívio da pobreza", aliás, o fenômeno educativo também 


\section{Autตaดูão}

ISSN: 1984-6444 | http://dx.doi.org/10.5902/1984644440558

consta no rol de desafios globais, dentre eles "melhorar a qualidade do ensino, a relevância da aprendizagem e uma boa educação". (1999, p. 7) Percebemos que o apelo da agência em relação à importância da educação na vida das pessoas distancia-se da perspectiva de garantir que todas tenham igualdade de condições para apropriar-se da cultura existente. $\mathrm{O}$ apelo aproxima-se do interesse em treinar os educandos para competir em "um mundo de rápidas mudanças". Assim, os argumentos de "oportunidades para todos", "educação como um direito humano", "informação para competir e prosperar", "qualidade adequada", "ensino de baixa qualidade", "currículo inapropriado" e "melhorar os resultados da aprendizagem" (1999, p. 8), tendem a camuflar os interesses de um organismo econômico, como o Banco, em fazer da educação um setor capaz de responder às diferentes necessidades do setor da economia, que se apresentam ao longo do processo histórico.

A insistência observada no documento em "melhorar a qualidade e a relevância da educação" associa-se á ideia de "acesso a ensino e aprendizagem de qualidade". Para tanto, o destaque às "parcerias produtivas" (1999, p, 7/8), como possibilidade de garantir essa pretensa qualidade da educação, do ensino e da aprendizagem, obscurece uma ideia de responsabilização coletiva acerca das questões educacionais. Diferente disso, é possível assinalarmos o crescente papel do setor privado - nomeadamente fundações e empresas privadas, segundo consta no documento -, na condição de um setor com práticas exitosas, cuja lógica vai sendo transferida para a educação, sob a justificativa de melhorar a qualidade. Encontramos conexão desse debate com as reflexões de Dardot e Laval (2016, p. 290, grifo dos autores) sobre os imperativos da razão neoliberal e o gerencialismo: "o postulado dessa nova 'governança' é que a gestão privada é sempre mais eficaz que a administração pública; que o setor privado é mais reativo, mais flexível, mais inovador, tecnicamente mais eficaz.

Além da ênfase às parcerias com o setor privado, como uma maneira de resolver problemas educacionais, a responsabilização individual também é enfatizada. O que fica implícito, nesse sentido, é uma retirada de cena do Estado, arquitetada ao passo em que ocorre a consolidação dos princípios neoliberais, bem 


\section{Althaห̧ão}

ISSN: 1984-6444 | http://dx.doi.org/10.5902/1984644440558

como, a tendência em responsabilizar os professores pelos escores atingidos pelos educandos nas avaliações. A perspectiva do Banco Mundial de individualizar a responsabilização como aposta em favor de uma responsabilização coletiva, a partir da soma das individuais, tem correspondência com ideias liberais oriundas do debate de Adam Smith.

Carnoy (2000) realiza um balanço da chamada doutrina liberal e pondera sobre as ideias de Smith. No sentido de coletivo como resultante da soma de individuais, o autor sublinha que

Smith não afirmou apenas que os vários motivos dos homens são traduzidos em um único desejo de ganho econômico. Ele acrescentou a isso o axioma fundamental de que cada indivíduo agindo em seu próprio interesse (econômico), quando colocado junto a uma coletividade de indivíduos, maximizaria o bem-estar coletivo. (CARNOY, 2000, p. 37).

Entendemos que a abordagem da ação e da responsabilização individual, percebida no documento como forma de melhorar os resultados educacionais, também encontra conexão com as reflexões de Stederoth (2017) sobre a formação ajustada. Nesse texto, o autor discute relações entre reformas da educação na Alemanha e os interesses da Organização para a Cooperação e Desenvolvimento Econômico (OCDE) em harmonizar os sistemas educacionais com a formação do capital humano. Embora a discussão trate de outro organismo internacional, ressaltamos como ponto convergente entre os receituários desta organização e do Banco Mundial, a ênfase à contínua adaptação dos países em relação às políticas educativas dessas agências.

Stederoth (2017) assinala a necessidade, criada a partir das reformas, para que os países ajustem-se a uma só estratégia: a fomentada pelos organismos econômicos. No caso das questões educacionais, reforça-se a tendência de as diretrizes estarem fundamentadas em conhecimentos estatísticos, pois propaga-se a ideia de assumir indicadores de qualidade para facilitar a comparação internacional. Ainda para o autor, "um sistema educativo assim ajustado às estruturas econômicas tem consequências diretas para o modelo e o dia a dia de nossos estabelecimentos educativos, na medida em que eles assumem, passo a passo, o caráter empresarial" (STEDEROTH, 2017, p. 497). 


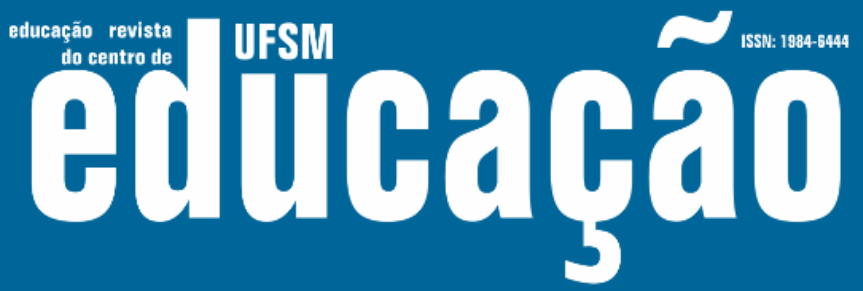

ISSN: 1984-6444 | http://dx.doi.org/10.5902/1984644440558

Sem perder de vista o Relatório... (1999) focalizado neste trabalho, destacamos que desenvolvimento não está vinculado à formação humana que faça frente à lógica capitalista e que leve em conta a ideia de mudança nos viveres, como sugere a perspectiva da autopoiese. Desenvolvimento, neste caso, refere-se ao campo econômico, no sentido de que dependemos dele e para conseguirmos alguma oportunidade no mercado, a educação torna-se uma necessidade global. O seguinte trecho do documento complementa nossa observação:

Face ao aumento da globalização, avanço da democracia, inovação tecnológica, emergência de novas economias de mercado, e mudança de papeis público/privado, países precisam de mais populações altamente educadas e competentes, e indivíduos precisam de mais competências e informações para competir e prosperar. (WORLD BANK, 1999, p. 8).

Em segundo lugar, a premissa educar para que as pessoas mudem o mundo aliada aos desafios globais listados pelo Banco, articulam-se à lógica de resultados, potencializada a partir do influxo neoliberal e de igual modo articulam-se às lógicas de servidão e de (de)formação humana. Tendo em conta o apelo à manutenção da economia de mercado, é possível inferir que a mensagem do documento neste ponto seja a seguinte: educação é para as pessoas mudarem o mundo econômico e, aqui, sugerimos a ideia de desempenho e produtividade -, melhorar a qualidade do ensino, a relevância da aprendizagem e uma boa educação que atendam as demandas da economia em um período histórico específico. Nessa direção, compreendemos que a ênfase não recai em fazeres pedagógicos e formativos cuja tônica seja a de profanar a dinâmica capitalista como ela se apresenta a partir da reestruturação produtiva.

Para Agamben (2007, p. 59), "profanar significa abrir a possibilidade de uma forma especial de negligência, que ignora a separação, ou melhor, faz dela um uso particular". Com base nesse autor, para nós, profanar implica em fazer da educação um meio que forme pessoas sensibilizadas em também mudar seus viveres, no sentido de negligenciar de alguma maneira os imperativos capitalistas, tais como eficiência, eficácia e desempenho, traduzidos pela máxima de melhores resultados como questões de sobrevivência. Estamos formando pessoas apenas para servirem ao capital? Para só cumprirem ordens? Para serem rotuladas pela produtividade? 


\section{Authaดูã}

ISSN: 1984-6444 | http://dx.doi.org/10.5902/1984644440558

Que qualidade de educação é essa, que, de acordo com o documento, vincula-se à competências para que os indivíduos sobrevivam e prosperem?

Compreendemos que a educação, valorizada pelo Banco, é a que visa "fabricar um sujeito neoliberal", expressão usada pelos autores Dardot e Laval (2016), e, ela está em conformidade com os pressupostos teóricos da modernidade. Inclusive, Libâneo (2005) contribui para complementar tal ideia, quando versa sobre a corrente pedagógica do tipo racional-tecnológica, caracterizando-a como concepção de neotecnicismo, cuja pedagogia está a serviço da formação para o sistema produtivo, pressupõe padrões de desempenho, tem como fundamento a racionalidade técnica e instrumental, e como centralidade o conhecimento em vista da sociedade tecnológica. Entendemos que nem todos os elementos do Relatório... (1999) tenham sido suficientemente refletidos neste trabalho. Ainda assim, consideramos que os pressupostos da modernidade são dominantes na abordagem do Banco Mundial e, nessa acepção, traduzir o conhecimento em resultados quantificáveis é uma preocupação central da agência, como uma das formas de conservar as relações capitalistas de produção.

\section{Algumas considerações}

Para além de discutir as configurações do papel do Estado a partir da contrarreforma dos anos 1990, refletir sobre pressupostos teóricos educacionais em paralelo à regulação por resultados tornou-se, em primeiro momento, um desafio, até mesmo por revisitar pressupostos de paradigmas diversos, o moderno e o contemporâneo. Entretanto, a oportunidade de reflexão tornou-se em seguida, um convite para pensar de outro modo os fazeres pedagógicos e as vivências investigativas que constituem o percurso formativo de um pesquisador.

Ao que se refere ao perfil mínimo-máximo do Estado imbricado na força capitalista potencializada pelos princípios neoliberais, entendemos que a educação é considerada mercadoria que precisa ser oferecida à população, ainda que seja uma etapa mínima, a fim de que as pessoas desenvolvam competências adequadas para inserirem-se no mercado de trabalho e para prosperar nele. Essa é a linguagem que 


\section{Althaห̧ão}

ISSN: 1984-6444 | http://dx.doi.org/10.5902/1984644440558

um dos documentos do Banco Mundial contém. Embora tenhamos focalizado a parte introdutória do relatório selecionado, ela ofereceu-nos indicativos de que a linguagem dessa organização que influencia na definição de políticas educacionais é a da empresa e o tom assumido no documento é o dos pressupostos modernos.

Vivenciamos o período de regulação por resultados: o Estado e a escola requerem resultados, melhorar as notas nas avaliações é sinal de uma educação qualificada. Mas, afinal, qualificada para quem e para que? Que formação humana é essa que pretende desenvolver competências em conformidade com as demandas do setor produtivo em um período histórico específico? Por que quantificar o saber tende a ser sinônimo de aprendizagem? O conhecimento pode ser traduzido apenas em fórmulas matemáticas e resultados? De que tipo de conhecimento estamos falando quando nos referimos à escola?

Sob pressupostos da modernidade, a ciência identifica-se pela produção de conhecimento que pode ser comprovado, pela separação entre natureza e ser humano, pela centralidade da matemática. Conhecer, nessa perspectiva, é ter condições de prever o comportamento dos fenômenos e, em última instância, é quantificar. $O$ projeto da ciência moderna envolve o equilíbrio, a ordem, a reversibilidade, contudo, também envolve uma lógica de pensar simplificadora, fragmentação de saberes, mascarada pela especialidade.

De outro modo, temos os pressupostos da contemporaneidade como suportes para fundamentar diferentes reflexões, bem como, perguntas potencializadoras de diferentes fazeres pedagógicos e formativos. Nessa perspectiva, valorizam-se o olhar do pesquisador, incertezas, imprevisibilidade, articulação, complexidade, desordem, auto-organização. Há o deslocamento da prerrogativa universalista para o reconhecimento de pluralidades, a fim de conhecer e compreender melhor o conhecimento, mas também, conhecer e compreender melhor o ser humano e seu potencial formativo.

Situado nesse conjunto, um dos desafios da educação escolar, a nosso ver, é extrapolar a justaposição de disciplinas, no sentido de trabalhar com integração de conceitos, de teorias e métodos de diferentes ciências, de modo a instigar a construção de conhecimentos e de vivências. Vivências em que não nos 


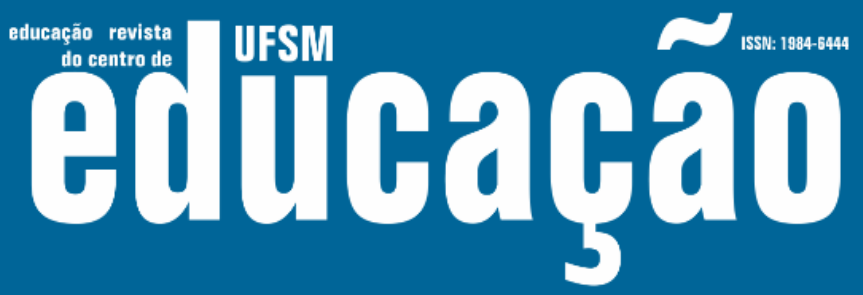

ISSN: 1984-6444 | http://dx.doi.org/10.5902/1984644440558

consideremos apenas como sujeitos em contínua competição e produtividade, como requer a fabricação do sujeito neoliberal sob a ótica capitalista. Do contrário, vivências investigativas que nos sensibilizem de que, ao invés de autônomos, em acepção de egoísmo, somos interdependentes, e, aqui, reforçamos uma ideia da autopoiese, de que dependemos do meio ao passo que ele também depende de nós.

Nesse sentido de pensar de outro modo, seria importante questionar os pressupostos em um movimento de pôr em questão e de pôr-se em questão, priorizando o exercício da impotência diante das exigências que o mercado dita e repercute em nós, nas políticas e nos processos educativos. Isto é, negar-se a permanecer contribuindo na produção de subjetividades flexibilizadas em acordo com as demandas do mercado, do individualismo e do consumismo é fazer frente e resistir às lógicas de servidão e de (de)formação humana.

A partir dos apontamentos realizados, consideramos que, ao invés de restringir as leituras a uma única perspectiva teórica, o desafio está em ampliar o leque de pressupostos, de modo a expandir o próprio conhecimento acerca do objeto de estudo e a enriquecer as vivências investigativas com outras reflexões.

\section{Referências}

AGAMBEN, Giorgio. Profanações. São Paulo: Boitempo, 2007.

BEHRING, Elaine Rossetti. Brasil em contra-reforma: desestruturação do Estado e perda de direitos. São Paulo: Cortez, 2003.

CARNOY, Martin. Estado e teoria política. 6. ed. Campinas, SP: Papirus, 2000.

DALE, Roger. Globalização e educação: demonstrando a existência de uma "Cultura Educacional Mundial Comum" ou localizando uma "Agenda Globalmente Estruturada para a Educação"? Educação e Sociedade., Campinas, v. 25, n. 87, p. 423-460, maio/ago. 2004.

DARDOT, Pierre; LAVAL, Christian. A nova razão do mundo: ensaio sobre a sociedade neoliberal. São Paulo: Boitempo, 2016.

HARVEY, David. O neoliberalismo: história e implicações. 2. ed. São Paulo: Edições Loyola, 2011. 


\section{usm

GAMBOA, Silvio Sanchez. Pesquisa Qualitativa: superando tecnicismos e falsos dualismos. Contrapontos, Itajaí, v. 3, n. 3, p. 393-405, set./dez. 2003.

LIBÂNEO, José Carlos. As teorias pedagógicas modernas revisitadas pelo debate contemporâneo na educação. 2005. Disponível em: https://www.fclar.unesp.br/Home/Graduacao/Espacodoaluno/PET-

ProgramadeEducacaoTutorial/Pedagogia/capitulo-libaneo.pdf. Acesso em: 11 jul. 2019.

MATURANA, Humberto; VARELA, Francisco. A árvore do conhecimento: as bases biológicas do entendimento humano. Campinas, SP: Editorial Psy II, 1995.

MATURANA, Humberto; VARELA, Francisco. De máquinas e seres vivos. Autopoiese: a organização do vivo. Porto Alegre: Artes Médicas, 1997.

MORIN, Edgar. Ciência com consciência. 8. ed. Rio de Janeiro: Bertrand Brasil, 2005. p. 175-194.

PRIGOGINE, Ilya; STENGERS, Isabelle. A nova aliança. 3. ed. Brasília: Editora UnB, 1997. p. 19-41.

SANTOS, Boaventura de Souza. Um discurso sobre as ciências. 5. ed. São Paulo: Cortez, 2008.

SCHAFF, Adam. História e verdade. São Paulo: Martins Fontes, 1995. p. 65-98.

STEDEROTH, Dirk. Formação ajustada: sobre a capitalização do humano na formação e sua administração total. Espaço Pedagógico, Passo Fundo, v. 24, n. 3, p. 487-507, set./dez. 2017.

WORLD BANK. Education Sector Strategy: World Bank Human Development Network. Washington, DC, 1999. Disponível em: http://documents.worldbank.org/curated/en/406991468178765170/Education-sectorstrategy. Acesso em: 11 jul. 2019.

\section{(C) $(1) \&$}

This work is licensed under a Creative Commons Attribution-NonCommercial 4.0 International (CC BY-NC 4.0)

\section{Notas}

\footnotetext{
${ }^{1} \mathrm{O}$ tema regulação por resultados vem sendo problematizado numa pesquisa maior, em processo, a partir de documentos produzidos pelo Banco Mundial, no período de 1990 a 2018. Já a construção dos apontamentos
} 


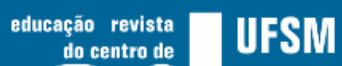

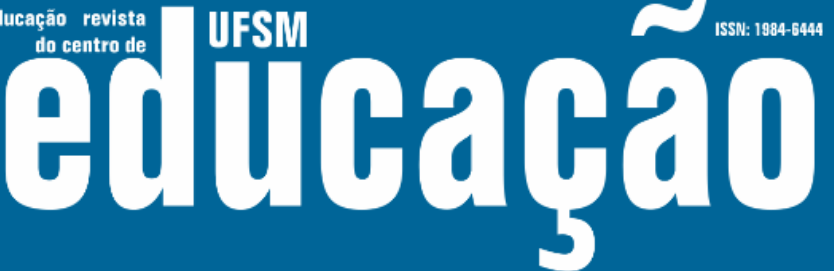

ISSN: 1984-6444 | http://dx.doi.org/10.5902/1984644440558

sobre a perspectiva teórica contemporânea foi instigada pelas reflexões realizadas na disciplina Teoria e Educação na Contemporaneidade, no primeiro semestre de 2019.

2 Tradução livre: Estratégia do Setor da Educação: Rede de Desenvolvimento Humano do Banco Mundial (1999). Além deste documento, outros estão sendo reunidos para compor o corpus documental de uma pesquisa maior que está em processo.

${ }^{3}$ As traduções do documento aqui apresentadas são traduções livres. 